Article

\title{
Association of mid sleep time and social jetlag with psychosocial behaviour of Indian population during COVID-19 lockdown
}

\author{
Meenakshi Sinha, Babita Pande, Ramanjan Sinha \\ Department of Physiology, All India Institute of Medical Sciences, Raipur, Chhattisgarh, India
}

\begin{abstract}
Background: India, being the third worst affected country from COVID-19 pandemic at the time of study, faced complete lockdown to minimize community transmission that confined people to social isolation for extended durations.

Design and Methods: Therefore, we conducted an online questionnaire-based survey for the Indian population after 37 days of complete lockdown to assess the integrative effects of such home restriction and social isolation on mid-sleep time, social jetlag, and their associated psychosocial behavior. From the reports of sleep onset and waking-up times before and during lockdown as obtained from a total of 1511 respondents of $\geq 18$ years, midsleep time (MST) and social jetlag (SJL) were calculated. Participants also rated their psychosocial behavior related variables on a Likert scale.

Results: Significantly delayed MST was noted during the lockdown. The majority showed reduced social jetlag; however, younger people and female subjects exhibited more SJL with delay in MST. Also, delayed MST and elevated SJL problems were more clearly demonstrated in people exhibiting more disturbances in sleep quality and daily routine, lower general mood status, irregular feeding habits (snacking frequency), worsened personal relationship, quality of life, and increased daydreaming events.

Conclusion: The study emphasizes the importance of maintaining a regular daily routine with respect to sleep-wake patterns and eating habits to minimize the impact of such a crisis situation on sleep behavior, social jetlag, and associated psychosocial wellbeing.
\end{abstract}

\section{Introduction}

The Coronavirus disease (COVID-19) outbreak worldwide and the imposed lockdown to prevent its community transmission has made the world a confinement zone. The extended duration of home confinement has isolated humans not only from social timings but also from natural photic zeitgebers (time givers). Therefore, in such instances, the individual is free to lead a selfchosen schedule of sleep-wake, digital and meal timing, physical activity, etc. just like weekends/holidays which creates a situation of social jetlag (SJL). SJL is the lag that persists in most of the individual's sleep-wake timings during weekdays and weekends and is calculated through the difference in mid-sleep times (MST) on weekends and weekdays. Mid sleep on free days is regarded as a reliable indicator of individual circadian preference for sleepwake timings. ${ }^{1}$ A later MST on free days indicates late circadian typology/chronotype/evening preference and an earlier MST on free days shows the morning chronotype or morning preference. On the other hand, SJL has been extensively studied in different age groups and correlated with sleep health, metabolic syndrome, and mental health. ${ }^{1-3}$

India is one of the worst-hit countries by the COVID-19 pandemic and Indian citizens had to face prolonged duration (March 25 to June 3, 2020) of lockdown/stay home restriction. Our latest report as a part of a national survey on Indians ${ }^{4}$ as well as other reports from Europe and the USA has documented alteration in sleep-wake patterns and increased digital media usage during lockdowns. ${ }^{5-7}$ However, the impact of such lifestyle changes leading to associated SJL as a function of MST on personal, psychological and family wellbeing needs to be addressed urgently for a timely intervention towards maintaining mental health. In this context, our earlier paper was focused exclusively to assess the impact of lockdown on the sleep-wake schedule and some of the associated lifestyle-related behavior such as digital media use and the major meal timings. ${ }^{4}$ Therefore, as a part of the same online national survey, we aimed to study the cause and effect relation between MST and SJL (lockdown jetlag) as a consequence of extended lockdown during COVID-19 pandemic with various psychosocial behavioral manifestations in the Indian population and also to assess if any correlation exists between the observed findings.

The study has both immediate and far-reaching significance. On the background of the ongoing COVID-19 pandemic, the study highlights the effect of the prolonged lockdown of a sizeable Indian population on the interaction of mid-sleep time and its associated social jetlag on some of their basic indicators of psychosocial behaviour. The finding reflects a significant influence of lockdown on sleep behaviour and its related effect which is suggestive of susceptibility to extreme psychological consequences in such conditions. Besides, the counsellors also need to take adequate steps keeping in view the heterogeneity in response across gender. Over the long term, this study provides a rare window of opportunity to obtain a scientific view of the effect of physical isolation which can be extrapolated to patients in the hospital, prisoners, sailors, or any other personnel mimicking prolonged lockdown conditions. The work schedules and mental states can thus be tailored to these effects which could increase productivity with reduction in altered psychological states. 


\section{Design and Methods}

The present cross-sectional questionnaire-based survey was conducted from April 01, 2020 to May 06, 2020 (i.e. after 37 days of lockdown) for the English and Hindi speaking population of India. On approval from institution ethics committee, participants were recruited by circulating the URL links of Google survey forms through social media platforms. The web survey was designed as per the guidelines of CHERRIES (PMID: 15471760; available at https://www.equator-network.org/). Informed consent was obtained from each participant as a part of questionnaire itself. Any subjects suffering from sleep disturbances, psychiatric disorders or on psychotropic drugs and pregnant women (as per their self-reporting through the questionnaire) were not included in the present study. Complete confidentiality regarding their identity was maintained.

\section{Measures}

Thirty relevant questions related to sleep-activity pattern and social/personal/psychological wellbeing were developed and validated as explained in our latest report. ${ }^{4}$ Total of 1511 participants were included for the study in the age range of 18 to 80 years [18-
24 y (796), 25-31 у (213), 32-38 y (158), 39-45 у (107), 46-52 у (101), 53-59 y (70), $\geq 60$ y (54) and undeclared (12)] which had 769 females, 738 males, and 4 unidentified genders. No participant was suffering from COVID-19 as per their self-report. A total of 18 items from the original 30 questions were used for the current analyses with 2 items on sleep onset and wakeup time, and 16 items on psychosocial behavior (shown in Table 1 as variables with response stratification). Findings from the rest of questions/items of the questionnaire related to sleep-wake schedule, meal timings and digital media exposure duration has been already published. ${ }^{4}$ MST was calculated as "sleep onset time + (sleep duration) $/ 2$ ". ${ }^{2}$ Further, SJL was calculated as "MST during lockdown-MST before lockdown" considering before lockdown situation as equivalent to weekdays and during lockdown situation as weekends. ${ }^{2}$

\section{Statistical analysis}

Paired and independent sample $t$-test was applied for within (before and during lockdown) and between groups (i.e. between genders and age groups) comparison respectively. Association between different groups was done by the Chi-square test, while Kendall's tau-b correlation was conducted to assess the relationship of MST and SJL with psychosocial variables that were in ordi-

Table 1. Comparison of mid sleep time (MST, in hour) and social jetlag (SJL, in hour) with psychosocial behaviour related variables during lockdown.

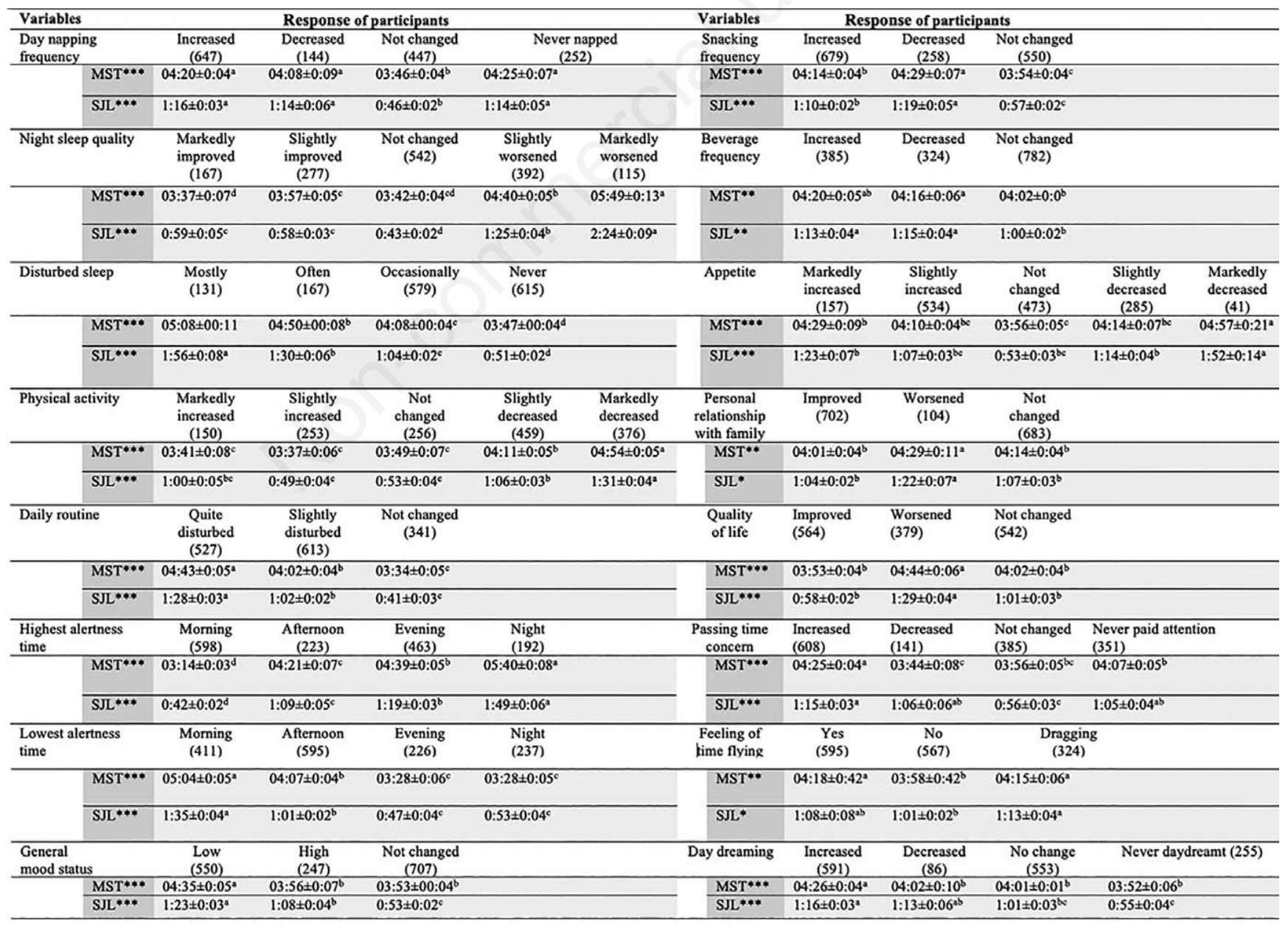

${ }^{* * *} \mathrm{p}<0.001,{ }^{* *} \mathrm{p}<0.01,{ }^{*} \mathrm{p}<0.05$ (ANOVA test displaying effect of psychosocial behaviour related variables on MST and SJL). Post-hoc analysis at the level of $\mathrm{p}<0.05$ denotes the significance of difference in mean change of studied variables across different levels. Highest to lowest mean indicated by ' $a$ ' to ' $d$ ' alphabets, where same alphabet indicates non-significant difference among groups. All the values are expressed as Mean \pm SE. Number of respondents indicated in parentheses. 
nal format. One-way ANOVA was conducted to assess the effect of factors, i.e. age and other psychosocial variables on mid-sleep and social jetlag followed by post-hoc Duncan's Multiple Range Test; $\mathrm{p} \leq 0.05$ was taken as significant.

\section{Results}

In this study, our data represents responses from people of 27 States and 5 Union Territories (UTs) of India out of 36 States and UTs (i.e., States $=28$ and UTs $=8$ ). Maximum respondents were from central India $(n=736 ; 49 \%)$ followed by south $(n=252 ; 17 \%)$, west $(n=193 ; 13 \%)$, east $(n=166 ; 11 \%)$ and north $(n=119 ; 8 \%)$ India.

\section{Mid sleep time and social jetlag}

Significant delay (during lockdown: 04:10 \pm 0:03 h and before lockdown: 03:25 $\pm 0: 02 \mathrm{~h}$ ) in MST during lockdown was observed $[t(\mathrm{df}, \mathrm{p})=19.42(1474,<0.001)]$. Also, a significant association between MST and the lockdown state was observed with the maximum number of respondents having MST in the time windows of 05:00-07:00 and $\geq 07: 00 \mathrm{~h}$ (Figure 1A). Whereas SJL as a consequence of lockdown was 1:07 $\pm 0: 02 \mathrm{~h}$, with the majority of people reporting less than $1 \mathrm{~h}$ of social jetlag (Figure 1B).

With regard to gender comparison, MST (before vs during lockdown) showed significant delay both in females and males (Figure 2A). Gender and MST was also significantly associated during lockdown $\left[\mathrm{c}^{2}(\mathrm{df}, \mathrm{p})=20.69(4,<0.001)\right]$ with majority having MST during 02:00-08:00 $\mathrm{h}$ (female $=304$; male $=303$ ). Significantly longer SJL was present in females during lockdown (Figure 2B), however no association of gender and SJL was detected $\left[\mathrm{c}^{2}(\mathrm{df}, \mathrm{p})=3.78(2,0.15) ; 00: 00-02: 00 \mathrm{~h}(\right.$ female $=573$, male $=$ 588); 02:00-04:00 h (female $=146$, male $=116) ; 04: 00-06: 00 \mathrm{~h}$ $($ female $=22$, male $=18)]$. Compared to males, females displayed significantly delayed MST and increased SJL during lockdown (Figures 2 A,B).

Age had a significant effect on MST both before and during lockdown (Figure 3A). Before lockdown, the youngest age group of 18-24y had significantly delayed MST. However, during lock-
$1 \mathrm{~A}$

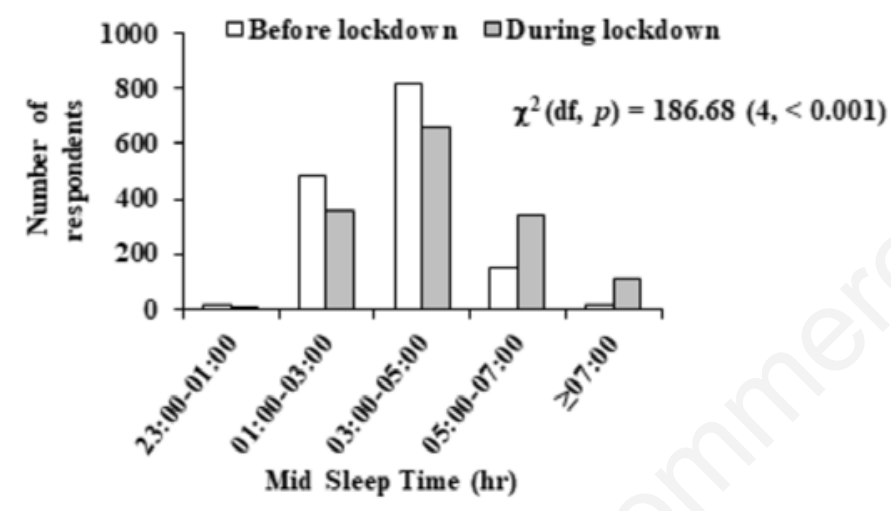

1B

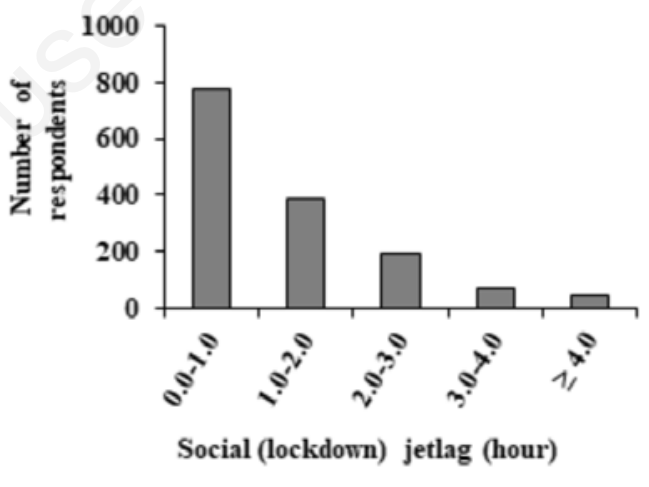

Figure 1. Distribution of number of respondents as function of mid sleep time before and during lockdown (A) and social (lockdown) jetlag (B). $\chi^{2}$ reveals significant association between mid sleep time and lockdown status, which was not seen for social (lockdown) jetlag.

$2 \mathrm{~A}$

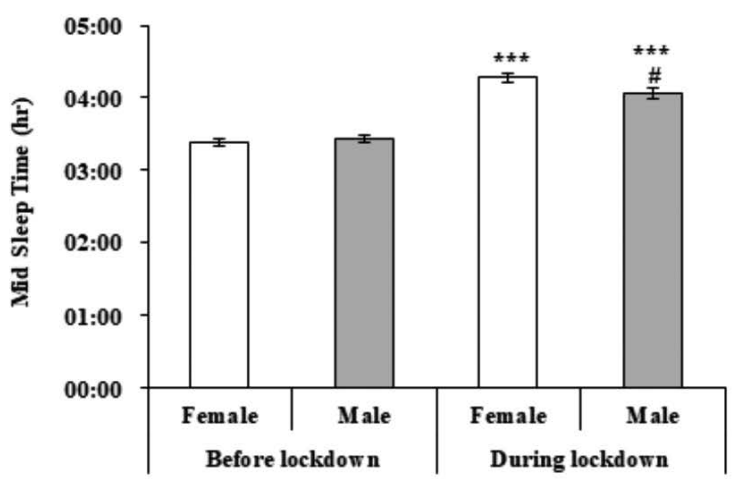

2B

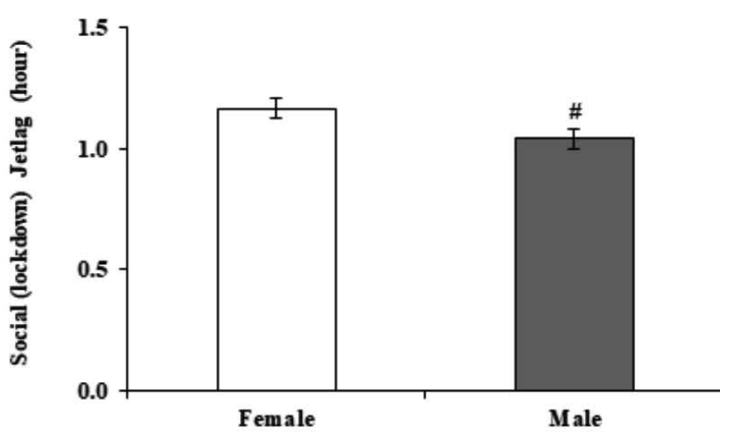

Figure 2. Comparison of mid sleep time before and during lockdown and social (lockdown) jetlag as function of gender (A, B). Significant difference was seen between before and during lockdown for both genders with females showing significantly higher mid sleep time compared to males during lockdown (A). Females also had significantly higher social (lockdown) jetlag (B); ${ }^{* * *}$ p $<0.001$ (within group) and $\# \mathbf{p}<0.05$ (between group). 
down, MST was significantly delayed in the individuals of both 18-24 y and 25-31 y age groups compared to rest of the age groups. The MST of age group 32-38 y was significantly delayed from $\geq 46$ $\mathrm{y}$ age groups, and that of $39-45 \mathrm{y}$ was significantly delayed from $\geq 53 \mathrm{y}$ of individuals (the age groups with the least delayed MST during lockdown and earlier MST compared to $\leq 39-45$ y ages). The age group 46-52 y showed significantly late MST than the $\geq 60$ $\mathrm{y}$ individuals only, but earlier MST in comparison to 18-24 y, 25$31 \mathrm{y}$ and $32-38 \mathrm{y}$.

However, in general, significantly late MST was observed for each age group during lockdown compared to before lockdown (Figure 3A). SJL was also significantly affected by age during lockdown with younger individuals between 18-31 y exhibiting longest $(1: 16 \pm 0: 04 \mathrm{~h})$ duration compared to age groups of 32-52 y (44 $\pm 5 \mathrm{~min}), 53-59$ y $(35 \pm 5 \mathrm{~min})$ and $\geq 60$ y ( $23 \pm 4 \mathrm{~min}$ ) (Figure 3B).

\section{Psychosocial behaviour}

Higher number of people reported increased daytime napping, worsened sleep quality, and disturbed sleep occasionally with decreased physical activity level and disturbed daily routine during lockdown (Table 1). The majority of people in all age groups exhibited the highest subjective alertness in the morning hours and lowest subjective alertness in the afternoon during lockdown with low general subjective mood status, increased frequency of eating/snacking, and slightly increased appetite during lockdown compared to before lockdown (Table 1). An improved personal relationship with other members of the family and improved quality of life was also seen in the maximum number of respondents during the lockdown. The number of people having concern towards the passage of time and with the feeling of time flying was also significantly high. The majority of people reported a significant increase in daydreaming (Table 1).

ANOVA depicted a significant impact of all the psychological/personal variables on MST and SJL during lockdown (Table 1). Post-hoc analysis showed significantly delayed MST and increased SJL in all subjects (except subjects with no change in frequency) irrespective of daytime napping frequency [MST: F (df, p) $=12.18(3,1465),<0.001$; SJL: F (df, p) = $19.03(3,1465),<0.001]$, in subjects with markedly worsened sleep quality (MST: F (df, p) = 55.89 (4, 1467), <0.001; SJL: F (df, p) = 71.99 (4, 1467), <0.001] and with maximum disturbed sleep [MST: F (df, p) $=33.92$ (3, 1467), <0.001; SJL: F (df, p) = 43.68 (3, 1467), <0.001] during lockdown. Same trend of delayed MST and more SJL was observed in the subjects reporting markedly decreased physical activity [MST: F (df, p) = $30.71(4,1467),<0.001 ;$ SJL: F (df, p) $=20.22$ $(4,1467),<0.001]$, disturbed daily routine [MST: F (df, p) $=52.43$ (2, 1456), <0.001; SJL: F (df, p) $=54.36(2,1456),<0.001]$, markedly decreased appetite $[\mathrm{MST}: \mathrm{F}(\mathrm{df}, \mathrm{p})=5.63(4,1463)$, $<0.001$; SJL: $\mathrm{F}(\mathrm{df}, \mathrm{p})=12.48(4,1463),<0.001]$, decreased frequency of snacking [MST: F (df, p) $=11.33(2,1463),<0.001$; SJL: $\mathrm{F}(\mathrm{df}, \mathrm{p})=10.18(2,1463),<0.001]$, decreased/increased beverages intake [MST: F (df, p)= 4.77 (2, 1466), 0.009; SJL: F (df, p) = 9.35 $(2,1466), 0.001]$, low mood status [MST: F (df, p) $=26.94(2$, 1460), <0.001; SJL: F (df, p) = $30.91(2,1460),<0.001]$, worsened personal relationship [MST: F (df, p) $=4.85(2,1465), 0.008$; SJL: $\mathrm{F}(\mathrm{df}, \mathrm{p})=3.86(2,1465), 0.050]$ and quality of life [MST: $F(d f, p)$ $=30.54(2,1461),<0.001 ;$ SJL: F (df, p) = $27.45(2,1461),<0.001]$, increased day dreaming [MST: F (df, p) = $8.51(3,1460),<0.001$; SJL: $\mathrm{F}(\mathrm{df}, \mathrm{p})=7.58(3,1460),<0.001]$, increased concern towards passing time $[\mathrm{MST}$ : $\mathrm{F}(\mathrm{df}, \mathrm{p})=9.83(3,1460),<0.001$; SJL: $\mathrm{F}(\mathrm{df}$, $\mathrm{p})=6.42(3,1460),<0.001]$, time flying [MST: $\mathrm{F}(\mathrm{df}, \mathrm{p})=6.19(2$, 1462), 0.002; SJL: F (df, p) = 3.59 (2, 1462), 0.03], highest alertness during night $[\mathrm{MST}$ : $\mathrm{F}(\mathrm{df}, \mathrm{p})=153.19(3,1450),<0.001$; SJL: $\mathrm{F}(\mathrm{df}, \mathrm{p})=62.42(3,1450),<0.001]$ and lowest alertness during morning hours [MST: $\mathrm{F}(\mathrm{df}), \mathrm{p}=69.29$ (3, 1443), <0.001; SJL: $\mathrm{F}$ (df), $\mathrm{p}=36.78(3,1443),<0.001]$ (Table 1).

Besides, significant association between different psychosocial behavioural parameters and gender was evident for many variables, i.e. sleep disturbances $(\mathrm{p}<0.05)$, physical activity level $(\mathrm{p}<0.001)$, highest subjective alertness time before lockdown $(p<0.001)$, general mood status $(p<0.05)$, beverages frequency and quality of life $(\mathrm{p}<0.01)$. The rest of the reported variables did not show a significant association with gender ( $p>0.05$; Table 2$)$. More females reported disturbed sleep with either increase or no change in physical activity level during lockdown compared to males $(p<0.001$; Table 2$)$. On the contrary, a greater number of males reported decreased physical activity levels during lockdown com-
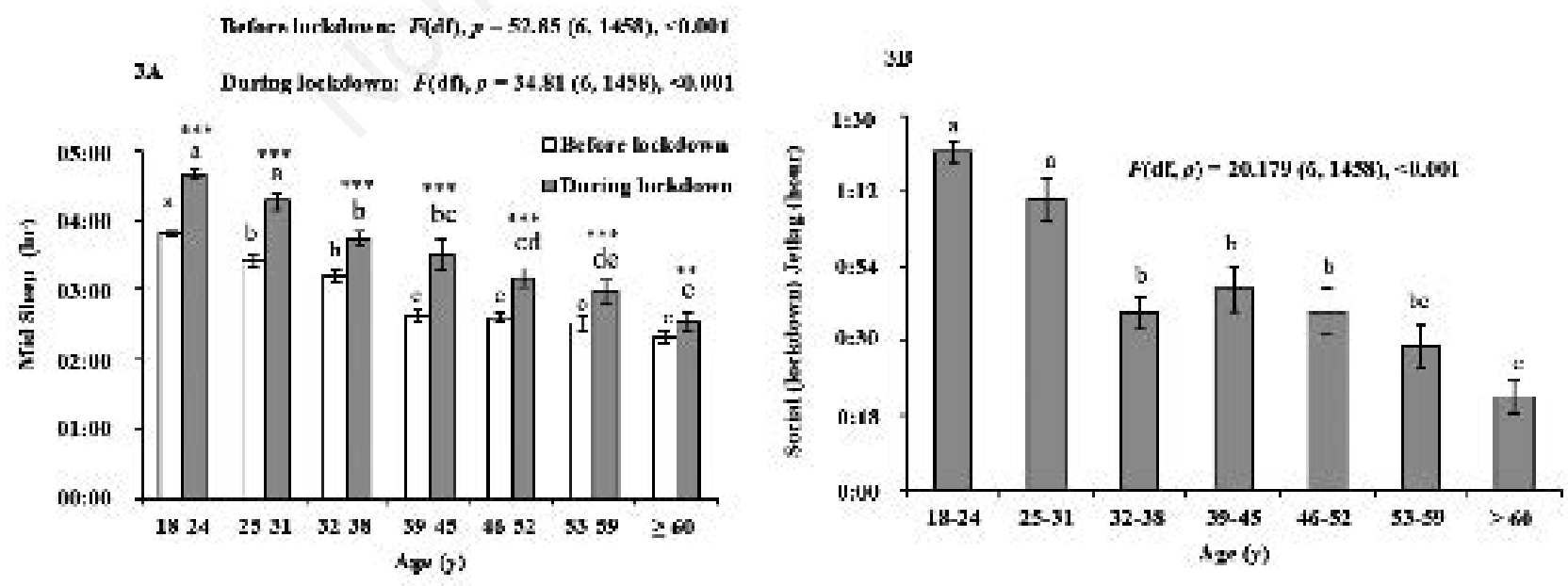

Figure 3. Comparison of mid sleep time before and during lockdown and social (lockdown) jetlag as function age. Significantly $(* *$ p $<0.01$; ${ }^{* * *} \mathrm{p}<\mathbf{0 . 0 0 1}$ ), delayed mid sleep time was seen during lockdown across each age groups. While post-hoc analysis at the level of $\mathrm{p}<0.05$ denotes the significance of difference in mean change of studied variables across different age groups for mid sleep time (A) and social (lockdown) jetlag (B) both before and during lockdown. Highest to lowest mean indicated by 'a' to ' $\mathrm{e}$ ' alphabets, where same alphabet indicates non-significant difference among age groups. All the values are expressed as Mean $\pm \mathrm{SE}$. 
Table 2. Chi-square test for the association between psychosocial behaviour and gender during lockdown.

\begin{tabular}{|c|c|c|c|c|}
\hline Variables & Responses & $\begin{array}{l}\text { Number } \\
\text { Female }\end{array}$ & $\begin{array}{l}\text { pondents } \\
\text { Male }\end{array}$ & Chi-Square value (df, p) \\
\hline Day napping frequency & $\begin{array}{l}\text { Increased } \\
\text { Decreased } \\
\text { Not changed } \\
\text { Never napped }\end{array}$ & $\begin{array}{l}325 \\
75 \\
236 \\
126\end{array}$ & $\begin{array}{l}324 \\
71 \\
214 \\
127\end{array}$ & $0.74(3,0.86)$ \\
\hline Night sleep quality & $\begin{array}{l}\text { Markedly improved } \\
\text { Slightly improved } \\
\text { Not changed } \\
\text { Slightly worsened } \\
\text { Markedly worsened }\end{array}$ & $\begin{array}{c}87 \\
132 \\
277 \\
205 \\
63\end{array}$ & $\begin{array}{c}80 \\
145 \\
269 \\
191 \\
52\end{array}$ & $2.08(4,0.72)$ \\
\hline Disturbed sleep & $\begin{array}{l}\text { Mostly } \\
\text { Often } \\
\text { Occasionally } \\
\text { Never }\end{array}$ & $\begin{array}{c}80 \\
95 \\
300 \\
289\end{array}$ & $\begin{array}{l}53 \\
73 \\
281 \\
329\end{array}$ & $11.05(3,0.011)$ \\
\hline Physical activity & $\begin{array}{l}\text { Markedly increased } \\
\text { Slightly increased } \\
\text { Not changed } \\
\text { Slightly decreased } \\
\text { Markedly decreased }\end{array}$ & $\begin{array}{c}97 \\
144 \\
140 \\
205 \\
179\end{array}$ & $\begin{array}{c}55 \\
110 \\
117 \\
256 \\
199\end{array}$ & $24.40(4,<0.001)$ \\
\hline Daily routine & $\begin{array}{l}\text { Quite disturbed } \\
\text { Slightly disturbed } \\
\text { Not changed }\end{array}$ & $\begin{array}{l}272 \\
311\end{array}$ & $\begin{array}{l}257 \\
303 \\
176\end{array}$ & $\begin{array}{c}0.069(2,0.97) \\
170\end{array}$ \\
\hline Highest alertness time before lockdown & $\begin{array}{l}\text { Morning } \\
\text { Afternoon } \\
\text { Evening } \\
\text { Night }\end{array}$ & $\begin{array}{c}465 \\
61 \\
160 \\
64\end{array}$ & $\begin{array}{l}403 \\
106 \\
146 \\
67\end{array}$ & $16.74(3,0.001)$ \\
\hline Highest alertness time during lockdown & $\begin{array}{l}\text { Morning } \\
\text { Afternoon } \\
\text { Evening } \\
\text { Night }\end{array}$ & $\begin{array}{l}291 \\
102 \\
255 \\
102\end{array}$ & $\begin{array}{c}303 \\
118 \\
210 \\
91\end{array}$ & $5.86(3,0.12)$ \\
\hline Lowest alertness time before lockdown & $\begin{array}{l}\text { Morning } \\
\text { Afternoon } \\
\text { Evening } \\
\text { Night }\end{array}$ & $\begin{array}{l}142 \\
292 \\
175 \\
141\end{array}$ & $\begin{array}{l}137 \\
272 \\
150 \\
160\end{array}$ & $3.27(3,0.35)$ \\
\hline Lowest alertness time during lockdown & $\begin{array}{l}\text { Morning } \\
\text { Afternoon } \\
\text { Evening } \\
\text { Night }\end{array}$ & $\begin{array}{l}227 \\
298 \\
120 \\
105\end{array}$ & $\begin{array}{l}184 \\
298 \\
107 \\
130\end{array}$ & $7.252(3,0.06)$ \\
\hline General mood status & $\begin{array}{l}\text { Low } \\
\text { High } \\
\text { Not changed }\end{array}$ & $\begin{array}{l}301 \\
101 \\
359\end{array}$ & $\begin{array}{l}252 \\
129 \\
351\end{array}$ & $7.28(2,0.026)$ \\
\hline Snacking frequency & $\begin{array}{l}\text { Increased } \\
\text { Decreased } \\
\text { Not changed }\end{array}$ & $\begin{array}{l}356 \\
122 \\
285\end{array}$ & $\begin{array}{l}324 \\
138 \\
270\end{array}$ & $2.25(2,0.32)$ \\
\hline Beverage frequency & $\begin{array}{l}\text { Increased } \\
\text { Decreased } \\
\text { Not changed }\end{array}$ & $\begin{array}{l}205 \\
140 \\
419\end{array}$ & $\begin{array}{l}181 \\
185 \\
369 \\
\end{array}$ & $10.34(2,0.006)$ \\
\hline Appetite & $\begin{array}{l}\text { Markedly increased } \\
\text { Slightly increased } \\
\text { Not changed } \\
\text { Slightly decreased } \\
\text { Markedly decreased }\end{array}$ & $\begin{array}{c}87 \\
271 \\
232 \\
150 \\
23\end{array}$ & $\begin{array}{c}70 \\
264 \\
244 \\
137 \\
20\end{array}$ & $2.51(4,0.64)$ \\
\hline Personal relationship with family & $\begin{array}{l}\text { Improved } \\
\text { Worsened } \\
\text { Not changed }\end{array}$ & $\begin{array}{c}352 \\
56 \\
356 \\
\end{array}$ & $\begin{array}{c}353 \\
49 \\
331 \\
\end{array}$ & $0.74(2,0.69)$ \\
\hline Quality of life & $\begin{array}{l}\text { Improved } \\
\text { Worsened } \\
\text { Not changed }\end{array}$ & $\begin{array}{l}267 \\
183 \\
311\end{array}$ & $\begin{array}{l}299 \\
198 \\
235\end{array}$ & $12.42(2,0.002)$ \\
\hline Passing time concern & $\begin{array}{l}\text { Increased } \\
\text { Decreased } \\
\text { Not changed } \\
\text { Never paid attention }\end{array}$ & $\begin{array}{l}315 \\
65 \\
206 \\
177\end{array}$ & $\begin{array}{c}295 \\
78 \\
182 \\
175\end{array}$ & $2.61(3,0.46)$ \\
\hline Feeling of time is flying & $\begin{array}{l}\text { Yes } \\
\text { No } \\
\text { Dragging }\end{array}$ & $\begin{array}{l}306 \\
302 \\
156\end{array}$ & $\begin{array}{l}291 \\
268 \\
171\end{array}$ & $2.32(2,0.13)$ \\
\hline Day dreaming & $\begin{array}{l}\text { Increased } \\
\text { Decreased } \\
\text { No change } \\
\text { Never day dreamt }\end{array}$ & $\begin{array}{c}307 \\
37 \\
285 \\
134\end{array}$ & $\begin{array}{c}286 \\
50 \\
268 \\
126\end{array}$ & $2.73(3,0.44)$ \\
\hline
\end{tabular}


pared to the female counterpart. Females displayed an increased frequency of taking tea/coffee/beverages $(p<0.001)$, while more males $(\mathrm{p}<0.01)$ reported improvement in their quality of life during lockdown (Table 2). The highest subjective alertness before the lockdown was during morning and evening hours for both the genders which became quite less for morning time in both, but markedly less $(p<0.0)$ for females (Table 2$)$. On the other hand, the majority (both genders) had the lowest alertness in the afternoon time before lockdown, which showed a shift towards morning time in many of the respondents ( $p>0.05$ ) during lockdown (Table 2).

Also, significant positive correlation of MST and SJL was observed with the psychosocial variables viz. day napping frequency $(p<0.05)$, disturbed sleep $(p<0.01)$, disturbed routine $(p<0.01)$, highest alertness time $(p<0.01)$, quality of life $(p<0.01)$, concern towards passing time $(p<0.01)$ and day dreaming $(p<0.01)$, whereas, significant negative relationship was present for night sleep quality $(p<0.01)$, physical activity level $(p<0.01)$, lowest alertness time $(\mathrm{p}<0.01)$, mood status $(\mathrm{p}<0.01)$ and personal relationship $(\mathrm{p}<0.01)$ during lockdown compared to before lockdown (Table 3 ).

\section{Discussion}

Our survey was conducted during complete lockdown (after 37 days) which was a reasonably effective time period to assess the consequences of lockdown. The present report emphasizes the interrelationship of mid-sleep and social jetlag (indicators of circadian misalignment and sleep-wake disturbances) with the psychosocial behaviour related factors.

\section{Mid sleep time and social (lockdown) jetlag}

We considered before-lockdown situation similar to normal working days/weekdays while complete lockdown as work-free days/holidays/weekends. Therefore, the SJL depicted here represents social (lockdown) jetlag. We report a significant delay in mid-sleep time during lockdown that was similar to the European study showing delayed mid-sleep during lockdown but only on working days (as people there worked from home in most of the sectors). ${ }^{5}$ However, in our survey, Indians showed more delayed MST (>15 min) compared to the above study demonstrating a higher impact of complete lockdown on the circadian sleep-wake preference. Delay in the midpoint of sleep during free days/holidays compared to working days has also been reported in individuals who were suffering from sleep loss and tried to compensate for the weekday's accumulated sleep debt on weekends. ${ }^{1}$ As this online survey was conducted following more than one month of lockdown, lack of synchronization of sleep-wake rhythm with natural light-dark cycle or social time cues is reflected in delayed MST. In synchronized state of sleep-wake rhythm with these cues, no delay in MST is expected. This was evident in our survey also, as majority of respondents before lockdown had early MST compared to during lockdown. As has been reported that an individu- als' circadian preference for sleep-wake timings on free days can be reliably indicated by the MST. ${ }^{1}$ Therefore, alteration in circadian preference in conditions with no access to natural light, a strong time cues or social cues shows misalignment or lack of synchronization of sleep-wake rhythm, a biological clock control process. A recent study from East India also showed a delayed trend in mid sleep during lockdown compared to before lockdown in University students and corporate sector professional adults. ${ }^{8}$

A substantial number of respondents' in our study had SJL of more than $1 \mathrm{~h}(1: 07 \pm 0: 02 \mathrm{~h})$ which points towards disturbed circadian sleep-wake rhythm during the lockdown. However, the majority showed less than $1 \mathrm{~h}$ of SJL, i.e. less SJL. Reduced SJL despite later sleep onset during working days has been documented in citizens of Argentina also. ${ }^{9}$ The lockdown seems to cause compensation of accumulated sleep deficit incurred during working days of pre-lockdown in our study subjects and thereby presents them with the opportunity to schedule associated daily activities as per their preferred circadian preference. We also noted the advancement of MST from younger to older age groups irrespective of lockdown status which can be explained based on morning preferences with aging. ${ }^{10,11}$ More pronounced SJL is reported in an individual with evening preference compared to morning preference due to more sleep debt in the former. ${ }^{12,13}$ Evening preference of younger people might be the reason for more SJL in younger adults compared to middle and older people in our study. ${ }^{4}$ Besides, better synchronization of older adults to external natural/societal cues might also be responsible for lesser desynchronization of biological rhythm. ${ }^{14}$ More SJL might also imply disturbed sleep-wake patterns and more sleep loss in young compared to aged. ${ }^{1,15}$

Delayed MST and higher SJL in females compared to males corroborates with our latest report suggesting higher susceptibility for alteration in the sleep-wake pattern during this lockdown which might be due to their longer digital time exposure during the lockdown. ${ }^{4}$ Besides, earlier reports have also purported compromised sleep health in females on account of domestic/cultural or hormonal cycle. ${ }^{13,16,17}$ More difference in mid-sleep before and during lockdown seems to cause higher social jetlag in females compared to male counterparts in our survey. Gender is known as one of the moderating factors for social jetlag through influencing sleep quality. ${ }^{18}$

\section{Psychosocial behaviour}

Low physical activity during lockdown with obviously reduced daylight exposure could be the reasons for worsened sleep quality and disturbances in our study as reported by others too. ${ }^{5,19}$ Such sleep deterioration was reflected in low general mood status and enhanced daytime napping during home confinement ultimately resulting in disturbed daily routine. Increased appetite with more snacking in the background of reduced physical activity and sleep disturbances could indicate serious health consequences later. A prolonged sedentary lifestyle during lockdown has been suggested to be responsible for many physical ailments also. ${ }^{8}$ More SJL has also been documented in some of the earlier reports on individuals

Table 3. Correlation-coefficient (Kendall's tau-b) of mid sleep time (MST, in hour) and social (lockdown) jetlag (SJL, in hour) with psychosocial behaviour related variables during lockdown

\begin{tabular}{|c|c|c|c|c|c|c|c|c|c|c|c|c|c|c|c|c|}
\hline Variabl & $\begin{array}{l}\text { Day } \\
\text { napping } \\
\text { frequency }\end{array}$ & $\begin{array}{l}\text { Night } \\
\text { sleep } \\
\text { quality }\end{array}$ & $\begin{array}{l}\text { Disturbed } \\
\text { sleep }\end{array}$ & $\begin{array}{l}\text { Physical } \\
\text { activity }\end{array}$ & $\begin{array}{l}\text { Daily } \\
\text { routine }\end{array}$ & $\begin{array}{l}\text { Highest } \\
\text { alertness } \\
\text { time }\end{array}$ & $\begin{array}{l}\text { Lowest } \\
\text { alertness } \\
\text { time }\end{array}$ & $\begin{array}{l}\text { General } \\
\text { mood } \\
\text { status }\end{array}$ & $\begin{array}{l}\text { Snacking } \\
\text { frequency }\end{array}$ & $\begin{array}{l}\text { Beverages } \\
\text { frequency }\end{array}$ & Appetite & $\begin{array}{l}\text { Personal } \\
\text { relationship } \\
\text { with family }\end{array}$ & $\begin{array}{l}\text { Quality of } \\
\text { life } \\
\text { concern }\end{array}$ & $\begin{array}{l}\text { Passing } \\
\text { time }\end{array}$ & $\begin{array}{l}\text { Feeling of } \\
\text { time flying }\end{array}$ & $\begin{array}{l}\text { Day } \\
\text { dreaming }\end{array}$ \\
\hline MST' & $0.054^{*}$ & $-0.222 * *$ & $0.204 * *$ & $-0.228 * *$ & $0.218^{* *}$ & $0.405^{* *}$ & $-0.281^{* *}$ & $-0.143^{* *}$ & -0.008 & 0.023 & 0.020 & $-0.060^{*}$ & $0.123^{* *}$ & $0.113^{* *}$ & 0.035 & $0.111^{* *}$ \\
\hline SIL & $0.052 *$ & $-0.232 * *$ & 0.238 ** & $-0.187^{* *}$ & $0.257^{* *}$ & $0.296 * *$ & $-0.206 * *$ & $-0.126^{* *}$ & -0.006 & -0.002 & 0.005 & -0.025 & $0.135 * *$ & $0.079^{* *}$ & 0.018 & $0.0933^{* *}$ \\
\hline
\end{tabular}

${ }^{*} p<0.01,{ }^{*} p 0.05$ (2-tailed). 
with diminished physical activity, ${ }^{20}$ adverse mental health, ${ }^{3}$ diminished sleep quality, mental and physical welfare during lockdown ${ }^{6}$, and/or increased stress level and boredom during lockdown corroborating our findings. ${ }^{5,21}$ An increased day time nap, increased stress, anxiety, and depression during lockdown have also been reported in adults from Eastern India and Italy. ${ }^{8,22}$ However, paradoxical to the sleep-associated problems, lockdown allowed better interaction/closeness with family improving the relationship and quality of life. For this reason, the majority of people felt the time was flying during the lockdown as happens during holidays when engaged in fun and/or self-chosen work/schedule. ${ }^{23}$ It might be also due to the late sleep-wake schedule and extended sleep duration in our subjects. ${ }^{4}$ However, longer free time also led to increased concern towards passing time and exhilarated daydreaming. The morning inclination of Indians due to cultural and geographical reasons could be responsible for morning peak and afternoon nadir for subjective alertness. ${ }^{24}$ Whereas, the shift of highest subjective alertness from the morning before lockdown to evening hours during lockdown could be reasoned to their delayed sleepwake pattern. ${ }^{25}$

Thus, as an extension of our latest report on the Indian population documenting altered sleep-wake, delayed mealtime, and increased digital media exposure, ${ }^{4}$ the present work further exhibits a trend of delayed mid-sleep with elevated social jetlag problems. These observed trends were found to be more pronounced in people displaying more of disturbances in psychologi$\mathrm{cal} /$ personal behaviour in terms of napping frequency, disturbed sleep quality and daily routine, lower general mood status, decreased appetite with binge eating, worsened personal relationship and quality of life, or increased daydreaming during the lockdown.

\section{Conclusions}

The present study is amongst the earliest reports on the impact of COVID-19 lockdown on the sleep and psychosocial behaviour of a fairly represented population of India. It is noteworthy here that individuals with lesser disturbances in personal wellbeing related parameters did not display delayed mid-sleep and had less social jetlag problem during the lockdown. We, therefore, advocate that following a regular daily routine related to sleep-wake pattern and meal timing during such a crisis when people are forced to partial/social isolation could mitigate sleep problems, social jetlag, and ensure psychological/personal wellbeing. The current study could be extrapolated to behavioural therapy and improving physical and mental wellbeing under similar situations like COVID-19 pandemic e.g., prolonged confinement due to posting at remote places during the war, expeditions or imprisonment. Also, such studies are relevant for understanding the behaviour of patients suffering from long term medical conditions with restrictive movements in general. However, the study could not consider the differential effect of abrupt lockdown on shift workers. Also, the scope for evaluation of psychosocial behaviour could be widened by including external behavioural manifestations such as domestic violence, anxiety, interpersonal relationships, and coping with restrictive stress. The study findings may be skewed by uneven distribution of subjects, most being from central and south India. Further, the findings may be skewed/more applicable to a younger age group as they represent the majority of the survey population. Thus, a pan Indian study addressing the aforesaid issues could be taken up in the future.
Correspondence: Dr. Meenakshi Sinha, Department of Physiology, All India Institute of Medical Sciences, Raipur 492099, Chhattisgarh, India. Mobile: +91.8518881709

E-mail: sinham66@aiimsraipur.edu.in

Key words: Mid sleep; social jetlag; quality of life; COVID-19 lockdown.

ContributionS: MS, concept and design, analysis and interpretation of data, drafting and revision of manuscript, final approval; BP, analysis and interpretation of data, drafting and revision of manuscript, final approval; RS, concept and design, critical revision of manuscript, final approval.

Funding: The present work was non-funded.

Acknowledgements: We acknowledge all the volunteers who participated in the online survey to make this study possible.

Conflict of interest: The authors declare no conflict of interest.

Ethics approval and consent to participate: The study was approved by the Institute Ethics Committee of All India Institute of Medical Sciences, Raipur, Chhattisgarh. Informed consent was obtained from each participant as a part of questionnaire itself.

Availability of data and material: The datasets used and/or analyzed during the current study are available from the corresponding author on reasonable request.

Patient consent for publication: The manuscript does not contain any individual person's data in any form.

Received for publication: 22 July 2020.

Accepted for publication: 1 November 2020.

oCopyright: the Author(s), 2020

Licensee PAGEPress, Italy

Journal of Public Health Research 2020;9:1870

doi:10.4081/jphr.2020.1870

This work is licensed under a Creative Commons Attribution NonCommercial 4.0 License (CC BY-NC 4.0).

\section{References}

1. Wittmann M, Dinich J, Merrow M, Roenneberg T. Social jetlag: Misalignment of biological and social time. Chronobiol Int 2006;23:497-509. doi: 10.1080/07420520500545979

2. Roenneberg T, Allebrandt KV, Merrow M, Vetter C. Social jetlag and obesity. Curr Biol 2012;22:939-43. doi: 10.1016/j.cub.2012.03.038

3. Henderson SEM, Brady EM, Robertson N. Associations between social jetlag and mental health in young people: A systematic review. Chronobiol Int 2019; 36:1316-33. doi: 10.1080/07420528.2019.1636813

4. Sinha M, Pande B, Sinha R. Impact of COVID-19 lockdown on sleep-wake schedule and associated lifestyle related behavior: A national survey. J Pub Health Res 2020;9:1826. doi: 10.4081/jphr.2020.1826

5. Cellini N, Canale N, Mioni G, Costa S. Changes in sleep pattern, sense of time and digital media use during COVID-19 lockdown in Italy. J Sleep Res 2020;e13074. doi: 10.1111/ jsr. 13074

6. Blume C, Schmidt MH, Cajochen C. Effects of the COVID-19 lockdown on human sleep and rest-activity rhythms. Curr Biol 
2020;30:R795-R797. doi: 10.1016/j.cub.2020.06.021

7. Gao C, Scullin MK. Sleep health early in the Coronavirus Disease 2019 (COVID-19) outbreak in the United States: Integrating longitudinal, cross-sectional, and retrospective recall data. Sleep Med 2020;73:1-10. doi: 10.1016/j. sleep.2020.06.032

8. Majumdar P, Biswas A, Sahu S. COVID-19 pandemic and lockdown: cause of sleep disruption, depression, somatic pain, and increased screen exposure of office workers and students of India. Chronobiol Int 2020;37:1191-200. doi: 10.1080/07420528.2020.1786107

9. María Juliana L, Mariano S, Diego Andrés G. Effects of lockdown on human sleep and chronotype during the COVID-19 pandemic. Curr Biol 2020;30:R930-1. doi: 10.1016/j.cub. 2020.07.015

10. Van Cauter E, Leproult R, Plat L. Age-related changes in slow wave sleep and REM sleep and relationship with growth hormone and cortisol levels in healthy men. JAMA 2000;284:8618. doi: 10.1001/jama.284.7.861

11. Roenneberg T, Kuehnle T, Pramstaller PP, et al. A marker for the end of adolescence. Curr Biol 2004;14:R1038-9. doi: 10.1016/j.cub.2004.11.039

12. Roenneberg T, Pilz LK, Zerbini G, Winnebeck EC. Chronotype and social jetlag: A (self-) critical review. Biology (Basel) 2019;8:54. doi: 10.3390/biology8030054 .

13. Pande B, Parveen N, Parganiha A, Pati AK. Shortening of sleep length and delayed mid-sleep on free days are the characteristic features of predominantly morning active population of Indian teenagers. Sleep Biol Rhythms 2018;16:431-39. doi: 10.1007/s41105-018-0173-7

14. Waleriańczyk W, Pruszczak D, Stolarski M. Testing the role of midpoint sleep and social jetlag in the context of work psychology: An exploratory study. Biol Rhythm Res 2020;51:1026-43. doi: 10.1080/09291016.2019.1571707

15. Roenneberg T, Merrow M. Entrainment of the human circadian clock. Cold Spring Harb Symp Quant Biol 2007;72:293-9. doi: 10.1101/sqb.2007.72.043

16. Park YM, Matsumoto K, Seo YJ, et al. Changes of sleep or waking habits by age and sex in Japanese. Percept Mot Skills. 94:1199-213. doi: 10.2466/pms.2002.94.3c.1199.

17. Shechter A, Varin F, Boivin DB. Circadian variation of sleep during the follicular and luteal phases of the menstrual cycle. Sleep 2010;33:647-56. doi: 10.1093/sleep/33.5.647

18. Raman S, Coogan AN. A cross-sectional study of the associations between chronotype, social jetlag and subjective sleep quality in healthy adults. Clocks Sleep 2020;2:1-6. doi: 10.3390/clockssleep2010001

19. Altena E, Baglioni C, Espie CA, et al. Dealing with sleep problems during home confinement due to the COVID-19 outbreak: Practical recommendations from a task force of the European CBT-I Academy. J Sleep Res 2020;e13052. doi: $10.1111 /$ jsr. 13052

20. Rutters F, Lemmens SG, Adam TC, et al. Is social jetlag associated with an adverse endocrine, behavioral, and cardiovascular risk profile? J Biol Rhythms 2014;29:377-83. doi: 10.1177/0748730414550199

21. Ogden RS. The passage of time during the UK Covid-19 lockdown. PLoS One 2020;15:e0235871. doi: 10.1371/journal. pone. 0235871

22. Gualano MR, Moro GL, Voglino G, et al. Effects of Covid-19 lockdown on mental health and sleep disturbances in Italy. Int J Environ Res Public Health 2020;17:E4779. doi: 10.3390/ijerph17134779

23. Simen P, Matell M. Why does time seem to fly when we're having fun? Science 2016;354:1231-2. doi: 10.1126/science. aal4021

24. Pati AK, Parganiha A, Reinberg A. Shift work: consequences and management. Curr Sci 2001;81:32-52.

25. Natale V, Cicogna P. Circadian regulation of subjective alertness in morning and evening types. Pers Individ Differ 1996;20:491-97. doi: 10.1016/0191-8869(95)00213-8. 